\title{
ASSESSMENT OF SPEECH AND LANGUAGE DELAY AMONG 0 - 3 YEAR OLD CHILDREN USING LANGUAGE EVALUATION SCALE, TRIVANDRUM
}

\author{
Swapna K. Pillai', Veena Anand², Sreedevi Babu ${ }^{3}$
}

${ }_{1}^{1}$ Assistant Professor, Department of Paediatrics, Sree Gokulam Medical College, Venjarammoodu, Thiruvananthapuram. ${ }^{2}$ Assistant Professor, Department of Paediatrics, Sree Gokulam Medical College, Venjarammoodu, Thiruvananthapuram. 3 Professor, Department of Paediatrics, Sree Gokulam Medical College, Venjarammoodu, Thiruvananthapuram.

\section{ABSTRACT}

\section{BACKGROUND}

Communication ${ }^{1}$ is vital for both biological and social existence. Speech and language is a complex brain function. Language ${ }^{2}$ refers to the entire system of expressing and receiving information in a way that is meaningful and includes verbal, non-verbal and written forms, while speech is the audible manifestation of language and includes physical movement of lips, tongue and cords to produce sounds. Delay 3 in acquiring language development is often an early and most sensitive indicator of intellectual disability, pervasive developmental disorder and specific learning disorders. Abnormalities in speech and language should be detected during the early stages of life itself, so that early intervention could be instituted. The critical period for speech development is till 3 years of age. Children ${ }^{4}$ with speech and language delays develop speech or language in the correct sequence but at a slower rate than expected, whereas children with speech and language ${ }^{2}$ disorders develop speech and language that is qualitatively different from typical development. Differentiating 5 between delays and disorders can be complicated. For this it is important to have sensitive ${ }^{6}$ screening tests, which can detect subtle developmental abnormalities. Such tools should be simple so that they can be administered even by health workers after sufficient training and this practice should be implemented even at the primary health care level. Early intervention is very important to improve the final outcome. Tools like LEST are very important in this respect. Both receptive and expressive aspects of speech can be analysed using this tool. Speech assessment ${ }^{7}$ should be made an integral part of the development assessment programmes. Paediatricians, health professionals and parents should be made aware of speech evaluation and its importance.

The aim of this study was to assess the prevalence of speech and language delay among 0 - 3 year old children and its association with antenatal and natal risk factors.

\section{MATERIALS AND METHODS}

Type of Study- Descriptive study.

Reference Population- Children in the age group of 0 - 3 years in Thiruvananthapuram district.

Source Population- Children attending the well-baby clinic in Sree Gokulam Medical College who were willing to participate in the study.

Study Sample and Sample Size

Inclusion Criteria- 200 children in the age group of 0 - 3 years attending the well-baby clinic and willing to participate in the study. Exclusion Criteria- Children with physical abnormalities, hearing loss or previously diagnosed developmental problems.

\section{RESULTS}

Of the 200 children studied, 22 had language delay (11\%). Maximum one item delay was in the 19 - 24 months' age group (50\%); two or more item delay was maximum seen in 13 - 18 months' age group (35.7\%) and 19 - 24 months' age group (28.5\%).

\section{CONCLUSION}

The prevalence of language developmental delay is $11 \%$. There is no significant association between antenatal, natal or post-natal risk factors and language delay from this study.

\section{KEYWORDS}

Speech and Language Delay, Language Evaluation Scale, Risk Factor Assessment Questionnaire.

HOW TO CITE THIS ARTICLE: Pillai SK, Anand V, Babu S. Assessment of speech and language delay among 0 - 3 year old children using language evaluation scale, Trivandrum. J. Evolution Med. Dent. Sci. 2017;6(87):6016-6020, DOI: 10.14260/Jemds/2017/1308

Financial or Other, Competing Interest: None.

Submission 07-06-2017, Peer Review 12-07-2017,

Acceptance 18-07-2017, Published 30-10-2017.

Corresponding Author:

Dr. Swapna K. Pillai,

Sreesivam, Villa No. 2, Sudarsana Villas,

Near Kavinkulangara Devi Temple, Karikakkam,

Thiruvananthapuram-695021.

E-mail: swpna.pillai@gmail.com

DOI: $10.14260 /$ jemds $/ 2017 / 1308$

\section{BACKGROUND}

Assessment $8,9,10$ of speech and language is of paramount importance in young children below 3 years; $90 \%$ of brain development is complete by 3 years. An easy, handy, ready to use tool should be available to make the assessment feasible in a busy OP setting. Due to various reasons, prevalence ${ }^{11,12}$ of speech delay is on the rise. Studying the exact prevalence in a community setting will help us to device new strategies for management of this problem. 


\section{MATERIALS AND METHODS}

Type of Study

Descriptive Study

\section{Reference Population}

Children in the age group 0 - 3 years in Thiruvananthapuram district.

\section{Source Population}

Children attending the well-baby clinic in Sree Gokulam Medical College who were willing to participate in the study.

\section{Study Sample and Sample Size \\ Inclusion Criteria}

200 children in the age group 0 - 3 years attending the wellbaby clinic and willing to participate in the study.

\section{Exclusion Criteria}

Children with physical abnormalities, hearing loss or previously diagnosed developmental problems.

\section{Tools}

Language evaluation scale for 0 - 3 years, risk factor assessment questionnaire, bell, rattle, toys, pictures.

\section{Data Collection}

200 children who came to the well-baby clinic were screened using Language evaluation screening test ( 0 - 3 years), which contains 33 items after obtaining permission from parents. Credits were awarded if the child passes each item correctly. The mothers were also interviewed. Response to certain items were recorded as reported by the mother. If the child did not cooperate, the child was asked to come for a second session. All the tests were administered by a single observer. Based on this the children were classified into normal (no delay), those with one delay and those with 2 or more delays. The total prevalence of language delay was calculated. The mothers were also administered the risk factor assessment questionnaire to assess the risk factors for language delay. The association between different parameters in the risk factor assessment questionnaire and language delay was studied using chi-square test.

\section{Outcome Variables}

The outcome variables of LEST are,

1. Normal: All items done.

2. One item not done.

3. Two or more items not done.

\section{RESULTS}

This study was done among 200 children attending well-baby clinic in Sree Gokulam Medical College, Thiruvananthapuram.

\begin{tabular}{|c|c|c|c|}
\hline Age in Months & Male & Female & Total \\
\hline $1-6$ & 23 & 17 & 40 \\
\hline $7-12$ & 44 & 23 & 67 \\
\hline $13-18$ & 17 & 15 & 32 \\
\hline $19-24$ & 15 & 15 & 30 \\
\hline $25-30$ & 9 & 7 & 16 \\
\hline $31-36$ & 12 & 3 & 15 \\
\hline Total & 120 & 80 & 200 \\
\hline \multicolumn{4}{|c|}{$\begin{array}{l}\text { Table 1. Distribution of Children } \\
\text { according to Age in Months }\end{array}$} \\
\hline
\end{tabular}

Out of the 200 children, 120 were males and 80 were females.

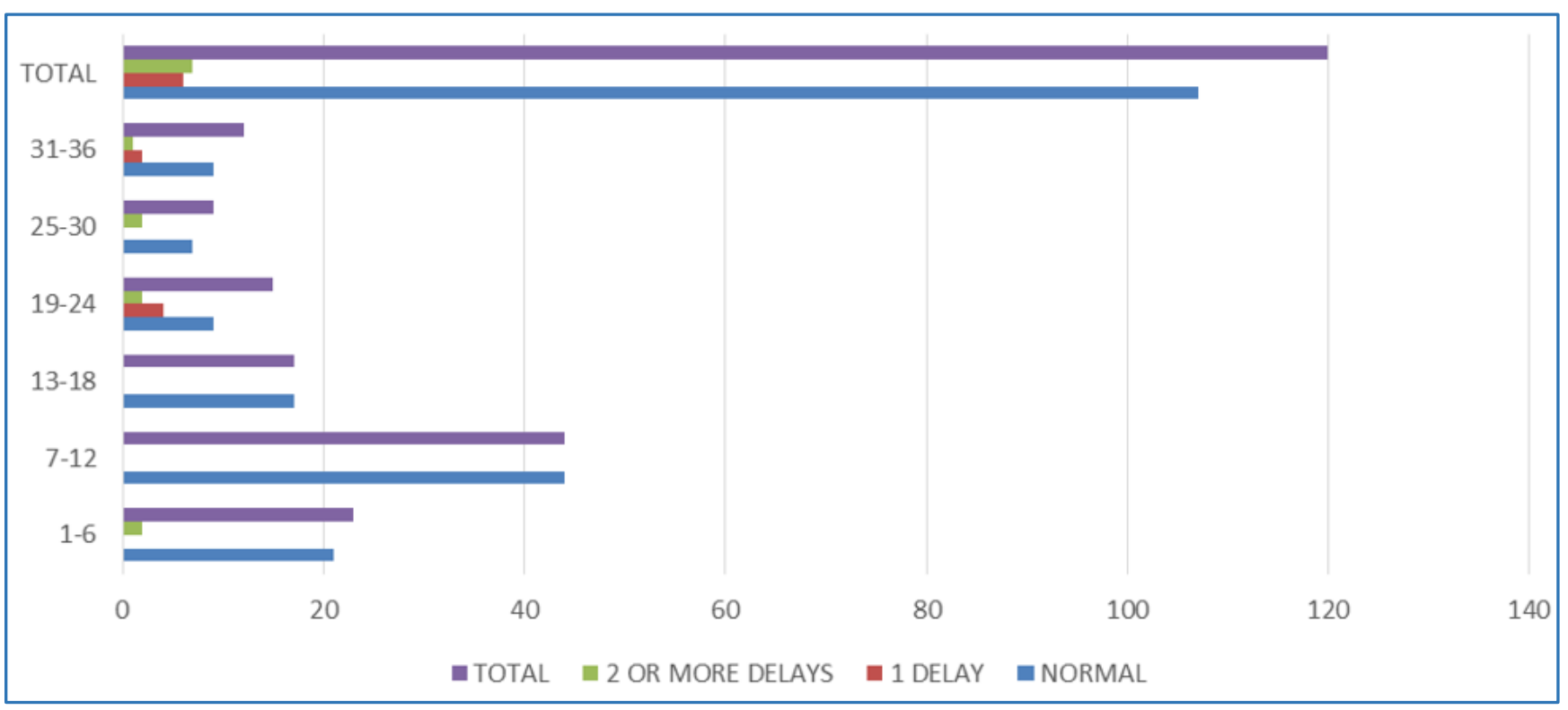

Figure 1. Distribution of Language Delay in Males in different Age Groups

6 children had 1 delay (5\%) and 7 children had 2 or more delays (5.8\%); 107 children were normal; 1 delay was maximum seen in children in the age group 19 - 24 months, while 2 or more delays were seen in 1 - 6 months, 19 - 24 months and 25 - 30 months. Total delay in males was $10.3 \%$. 


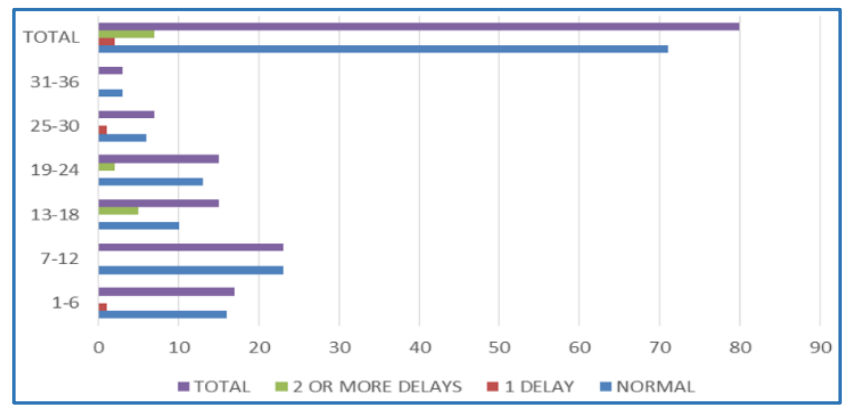

Figure 2. Distribution of Language Delay in Females in different Age Groups

Out of the 80 female children, 2 had 1 item delay (2.4\%) and 7 had 2 or more items delay (8.8\%); 1 item delay was seen in 1 - 6 months' age group and 25 - 30 months' age group; 2 or more items delay was seen maximum in 13 - 18 months' age group and 19 - 24 months' age group. Total delay in females was $11.2 \%$. There was no significant difference in delay between males and females.

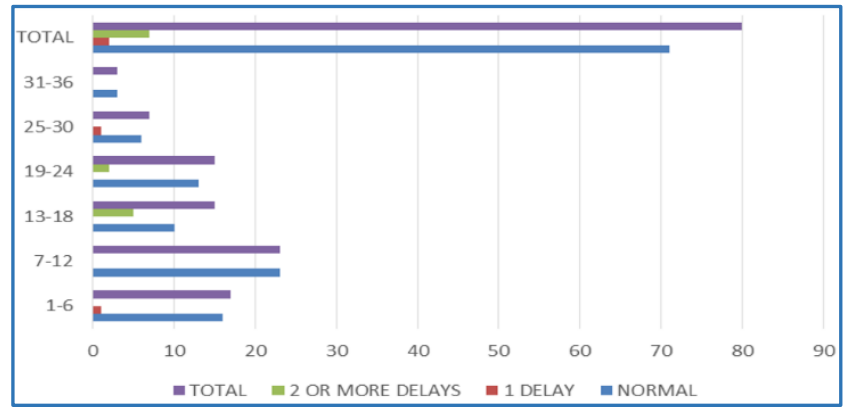

Figure 3. Total Distribution of Language Delay in different Age Groups

Of the 200 children studied, 22 had language delay (11\%). Maximum 1 item delay was in the 19 - 24 months' age group (50\%); 2 or more item delay was maximum seen in $13-18$ months' age group (35.7\%) and $19-24$ months' age group (28.5\%).

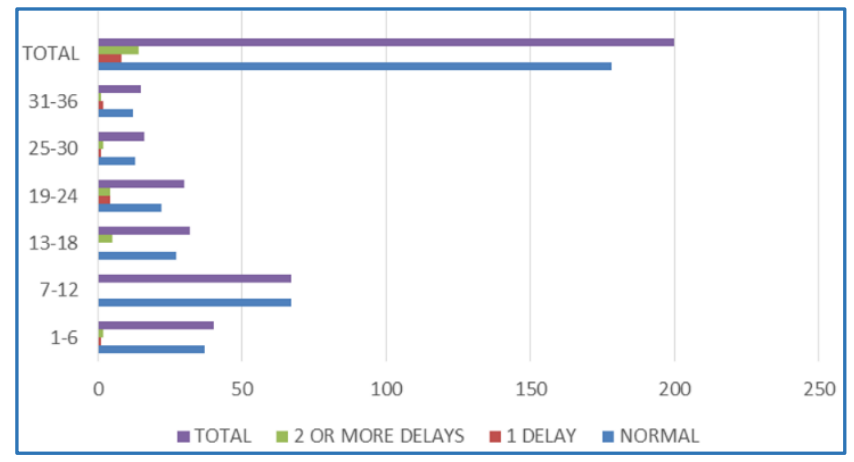

Figure 4. Figure showing Relation between Age and Language Delay

\begin{tabular}{|c|c|c|c|c|}
\hline $\begin{array}{c}\text { Birth } \\
\text { Weight in } \\
\text { KG }\end{array}$ & Normal & 1 Delay & $\begin{array}{c}\text { 2 or } \\
\text { More } \\
\text { Delays }\end{array}$ & Total \\
\hline$<=2.5$ & 26 & 1 & 1 & 28 \\
\hline $2.6-3$ & 82 & 3 & 9 & 94 \\
\hline $3.1-3.5$ & 54 & 4 & 4 & 62 \\
\hline$>3.5$ & 16 & 0 & 0 & 16 \\
\hline Total & $\mathbf{1 7 8}$ & $\mathbf{8}$ & $\mathbf{1 4}$ & $\mathbf{2 0 0}$ \\
\hline \multicolumn{4}{|c|}{ Table 2. Table showing Relation } \\
between Birth Weight and Language Delay \\
\hline
\end{tabular}

Of the 8 children with 1 item delay, 4 were with birth weight $3-3.5(50 \%)$ and 3 had birth weight of $2.6-3.0 \mathrm{~kg}$ (37\%). Of the 14 children with 2 or more item delay, 9 had a birth weight of $2.6-3 \mathrm{~kg} \mathrm{(64 \% )}$ and 4 had birth weight of 3.1 $3.5 \mathrm{~kg}(28 \%)$. Of all the children with delay, maximum delay was seen in children with birth weight of $2.6-3 \mathrm{~kg}$.

\begin{tabular}{|c|c|c|c|c|}
\hline $\begin{array}{c}\text { Type of } \\
\text { Delivery }\end{array}$ & Normal & 1 Delay & $\begin{array}{c}\text { 2 or More } \\
\text { Delays }\end{array}$ & Total \\
\hline Normal & 120 & 6 & 9 & 135 \\
\hline $\begin{array}{c}\text { Caesarean } \\
\text { and Assisted }\end{array}$ & 58 & 2 & 5 & 65 \\
\hline Total & $\mathbf{1 7 8}$ & $\mathbf{8}$ & $\mathbf{1 4}$ & $\mathbf{2 0 0}$ \\
\hline \multicolumn{5}{|c|}{$\begin{array}{c}\text { Table 3. Table showing relation between } \\
\text { Type of Delivery and Language Delay }\end{array}$} \\
\hline
\end{tabular}

Of the 200 children, 120 were born by normal delivery and 58 were born by CS. Of the 135 children born by normal delivery, 15 had language delay (11.1\%). Of the 58 children born by CS, 7 had language delay (12.1\%). There was no significant difference in delay between children born by normal delivery and CS with a $\mathrm{p}$ value of .94 by chi-square testing.

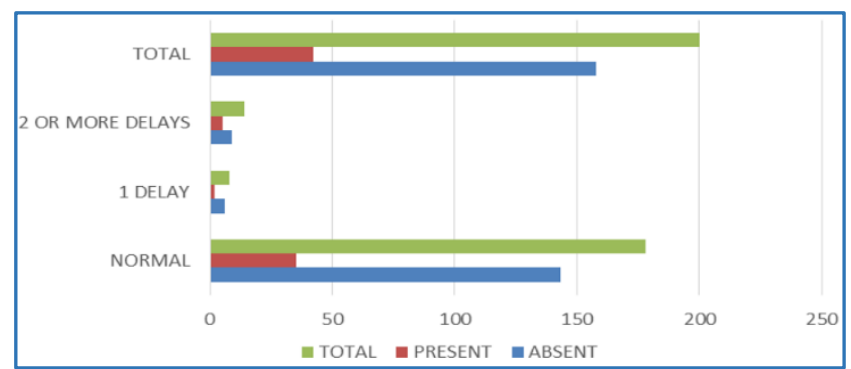

Figure 5. Figure showing the Relation

between Antenatal Risk Factors and Language Delay

Of the 200 children, 42 children had antenatal risk factors and 158 children had no risk factors. Among the 22 children with delay 7 had risk factors (31.8\%), while 15 had no risk factors (68\%). There was no significant association between antenatal risk factors and developmental delay with a $p$ value of .187 by chi-square testing.

\section{DISCUSSION}

Of the 200 children studied, 22 had language delay (11\%). Maximum 1 item delay was in the 19 - 24 months' age group (50\%); 2 or more item delay was maximum seen in $13-18$ months' age group (35.7\%) and 19 - 24 months' age group (28.5\%). This is higher than Stevenson and Richman (1976), who obtained a prevalence of $6 \%$ for language delay and Tomblin et al (1997) who obtained 7.4\% delay.

$5 \%$ male children had 1 item delay (5\%) and 5.8\% male children had 2 or more items delay; 1 delay was maximum seen in children in the age group 19 - 24 months in males, while 2 or more delays were seen in 1 - 6 months, $19-24$ months and 25 - 30 months. Total delay in males was $10.8 \%$.

Out of the 80 female children, $2.4 \%$ had 1 item delay and $8.8 \%$ had 2 or more items delay; 1 item delay was seen in 1 - 6 months' age group and 25 - 30 months' age group; 2 or more items delay was seen maximum in 13 - 18 months' age group and 19 - 24 months' age group. Total delay in females was 
$11.2 \%$. There was no significant difference in delay between males and females.

Prevalence of speech delay only ranges from 2.3 to $24.6 \%$. Kirkpatrick and Ward $^{7}$ (1984) identified $4.6 \%$ prevalence, while Beitchman et al (1986) got a prevalence rate of $6.4 \%$. In contrast, Tuomi and Ivanov (1977) adopted a criteria of 1 year behind chronological age and reported $24.6 \%$ in kindergarten children, although this fell to $16.5 \%$ by Grade 1 . These figures are relatively high and probably reflect the relatively liberal definition of what constitutes a case including children with poor 'stimulability.' Here children's speech is reported in absolute rather than developmental terms. For the age group of $3-4$ years in the study done by James et al, the speech and/or language delay was $5 \%$. In our study, it was $11 \%$ which was higher. For the age group of $5-6$ years, in the study by Beitchman et al the speech and/or language delay was $11.78 \%$. In another study by Stevenson et al, it was $6.8 \%$. In the present study, the speech delay was $11 \%$ which can be compared to the study done by Beithchman et al.

Stevenson and Richman ${ }^{13}$ 1976, Rescorla et al 1993 studies receptive and expressive delay, while Silva ${ }^{14}$ et al (1983) seek to identify expressive delay in the absence of delay in receptive language. Silva ${ }^{14}$ et al 1983 , Wong et al estimate prevalence as between $2 \%$ and $3 \%$, which remains constant across the age range. To ${ }^{15,16}$ classify children in this way it is necessary to use standardised procedures that tease apart expressive and receptive skills. Of all the children with delay, maximum delay is seen in children with birth weight of $2.6-3 \mathrm{~kg}$. There is no significant relation between birth weight and delayed skills. The figures reported by Stevenson and Richman, and Silva range from $2.34 \%$ to $4.27 \%$ over the age range of 3 - 7 years).

There was no significant association between antenatal risk factors and developmental delay with a $\mathrm{p}$ value of .187 by chi-square testing. Of all the children with delay, maximum delay is seen in children with birth weight of $2.6-3 \mathrm{~kg}$. There is no significant relation between birth weight and delay.

There is no significant difference in delay between children born by normal delivery and CS with a p value of .94 by chi-square testing.

\section{Recommendations}

The prevalence of $11 \%$ speech and language delay in the normal children enlightens the need for early screening programs. Because communication is central to personal development, social interaction and learning ability of child, delay in the language and speech development should be identified as early as possible. LEST should be used by paediatricians and health workers during routine visits of the child for early screening.

\section{CONCLUSION}

1. The prevalence of language developmental delay is $11 \%$.

2. The prevalence of 1 item delay alone is $36.36 \%$.

3. The prevalence of 2 or more items delay is $63.63 \%$; $89 \%$ children has normal development.

4. One delay is maximum seen in children in the age group 19 - 24 months.

5. There is no significant difference in delay between males and females.
6. Maximum delay is seen in children with birth weight 2.6 $3 \mathrm{~kg}$ with no significant relation to low birth weight.

7. There is no significant association between antenatal, natal or post-natal risk factors and language delay from this study.

\section{REFERENCES}

[1] Siu AL. Screening for speech and language delay and disorders in children aged 5 years or younger: US preventive services task force recommendation statement. Pediatrics 2015;136(2).

[2] Ellis EM, Thal DJ. Early language delay and risk for language impairment. Perspect Lang Learn Educ 2008;15(3):93-100.

[3] US Department of Education, Office of Special Education and Rehabilitative Services 2012. 31 st Annual Report to Congress on the Implementation of the Individuals with Disabilities Education Act, 2009.

[4] Pinborough-Zimmerman J, Satterfield R, Miller J, et al. Communication disorders: prevalence and comorbid intellectual disability, autism, and emotional/behavioral disorders. Am J Speech Lang Pathol 2007;16(4):359-67.

[5] Bashir AS, Scavuzzo A. Children with language disorders: natural history and academic success. J Learn Disabil 1992;25(1):53-70.

[6] Nelson HD, Nygren P, Walker M, et al. Screening for speech and language delay in preschool children: systematic evidence review for the US preventive services task force. Pediatrics 2006;117(2):e298-319.

[7] Halfon N, Olson L, Inkelas M, et al. Summary statistics from the national survey of early childhood health, 2000. Vital Health Stat 2002;15(3):1-27.

[8] Radecki L, Sand-Loud N, O'Connor KG, et al. Trends in the use of standardized tools for developmental screening in early childhood: 2002-2009. Pediatrics 2011;128(1):14-9.

[9] Berkman ND, Wallace I, Watson L, et al. Screening for speech and language delay and disorders in children age 5 years or younger. A systematic review for the U.S. preventive services task force. Evidence Synthesis No. 120. Rockville, MD: Agency for Healthcare Research and Quality; 2015. AHRQ Publication 13-05197-EF-1.

[10] Peterson RL, Pennington BF, Shriberg LD, et al. What influences literacy outcome in children with speech sound disorder? J Speech Lang Hear Res 2009;52(5):1175-88.

[11] Catts HW, Fey ME, Tomblin JB, et al. A longitudinal investigation of reading outcomes in children with language impairments. J Speech Lang Hear Res 2002;45(6):1142-57.

[12] Scarborough HS, Dobrich W. Development of children with early language delay. J Speech Hear Res 1990;33(1):70-83.

[13] Richman N, Stevenson J, Graham PJ. Pre-school to school: a behavioural study. London, United Kingdom: Academic Press; 1982. 


\section{Jemds.com}

[14] Silva PA, Williams S, McGee R. A longitudinal study of children with developmental language delay at age three: later intelligence, reading and behaviour problems. Dev Med Child Neurol 1987;29(5):630-40.

[15] Bishop DV, Clarkson B. Written language as a window into residual language deficits: a study of children with persistent and residual speech and language impairments. Cortex 2003;39(2):215-37.

\section{Original Research Article}

[16] Snowling MJ, Bishop DV, Stothard SE, et al. Psychosocial outcomes at 15 years of children with a preschool history of speech-language impairment. J Child Psychol Psychiatry 2006;47(8):759-65. 